\section{REGIONAL MEETING}

BDA East Midland Branch will hold their Annual General Meeting on Wednesday 7 October 2015 at 7:30 pm, prior to the educational meeting. The venue is Novotel, Long Eaton (junction $25 \mathrm{M} 1$ ), Bostock Lane, Long Eaton, NG10 4EP.

Further information or apologies can be sent to eastmidlandsbda@gmail.com

\section{SURVEY FINDS PATIENTS PRESENT 'CHALLENGING INTERACTIONS' ALL TOO FREQUENTLY}

A Dental Protection survey of 497 members found that $97 \%$ experience challenging interactions with patients - half of those encountering it monthly and one in three on a weekly basis. Fiftysix percent of respondents had experienced aggressive demands for treatment, $48 \%$ had received verbal abuse, and a further 39\% experienced violent or aggressive behaviour.

Challenging interactions were found to impact on $88 \%$ of respondents' practice working environment with 94\% believing it causes stress and anxiety amongst the dental team, 73\% feel it causes a fear of complaints and claims, and 67\% reported it leads to delays in appointments.

The majority of respondents (85\%) told us that they believe patient expectations are higher than they were five years ago and 50\% believe unmet patient expectations to be the most common reason for challenging encounters. Other top factors behind challenging interactions included the patient's aggressive temperament (43\%), a breakdown in communication between the dentist and patient (37\%), and the patient's anxiety about dental treatment (35\%).

Dental Protection Director, Kevin Lewis said: 'It is important that dentists are well equipped to deal with such challenges'.

\section{IN THE NEWS}

Have you ever noticed how dentistry never seems to go away? From absurd articles claiming eating 10,000 strawberries a day will help to whiten teeth to everyone's favourite topic - sugar, over the last four years dentistry has begun to dominate news. Here we take a look at some of the big topics currently in the news.

\section{Fluoride}

The news in a nutshell: The British Dental Health Foundation believe the findings of recent research into water fluoridation could be the springboard to lift the financial burden on the NHS.

Research published in Community Dentistry and Oral Epidemiology looked at areas which have fluoridation schemes in place and found that people living in these areas had 55\% fewer admissions for tooth extractions than those which didn't.

What they said: Chief Executive of the BDHF Dr Nigel Carter: 'Only around $12 \%$ of the UK population live in areas which have fluoridated water and the NHS has to pick up the burden when it comes to the consequences to our teeth.'

\section{E-cigarettes}

The news in a nutshell: Public Health England has officially recognised that 'on the best estimate so far', e-cigarettes are 95\% less harmful than cigarettes.

The review found that almost all of the 2.6 million adults in the UK now thought to be using e-cigarettes are current or former conventional smokers. There was no suggestion that the products were a gateway into tobacco smoking, with less than $1 \%$ of adults or young people who had never smoked becoming regular cigarette users.

What they said: Professor Kevin Fenton, director of health and wellbeing at Public Health England: 'E-cigarettes are not completely risk free but when compared to smoking, evidence shows they carry just a fraction of the harm. The problem is people increasingly think they are at least as harmful and this may be keeping millions of smokers from quitting.'

\section{NHS dental statistics}

The news in a nutshell: Half of adults have not been to the dentist - the first fall in patient numbers since 2013.

Figures released by the Health and Social Care Information Centre (HSCIC) showed 22 million adults and 8 million children visited the dentist - a slight fall on the previous year. One in four children received fluoride varnish treatment, and 45\% of adults had a scale and polish.

What they said: Professor Nigel Hunt, Dean Faculty of Dental Surgery: 'This data reveals a decade of inertia in access to dentistry. In the last two years approximately 50\% of adults and almost a third of children haven't seen a dentist. Routine visits to the dentist are vital to maintaining good oral health.

It's appalling that tooth decay remains the most common reason why five-to nine-year-olds are admitted to hospital; in some cases for multiple tooth extractions under general anaesthetic - despite tooth decay being almost entirely preventable.

'Visiting the dentist regularly is crucial in providing rapid diagnosis and treatment to prevent both children and adults from being hospitalised due to tooth decay.

'The new Government needs to urgently review why access is not improving and launch a national campaign to stress the importance of seeing a dentist.'

\section{Sugar}

The news in a nutshell: Coca Cola is partially funding a number of studies that emphasise the importance of exercise rather than sugary drinks in the nation's obesity crisis.

The soft drinks company has been accused of providing financial and logistical support to the Global Energy Balance Network (GEBN).

This group promotes the idea that exercise, rather than a healthy diet, is the key to health and

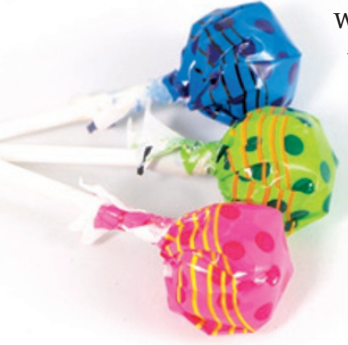
weight loss, claims which go against the word of critics who say that Coca Cola's sugary drinks are contributing to the global obesity and diabetes epidemics.

What they said: The Independent reported that the study's text likened the actions of the food industry to those used by the tobacco industry, and called for the endorsements of sugary drinks and the association of junk food with sport to stop. 